\title{
Quality of life of women with breast cancer
} undergoing treatment and follow-up at King Salman
Armed Forces Hospital in Tabuk, Saudi Arabia

This article was published in the following Dove Press journal: Breast Cancer: Targets and Therapy

\author{
Attiya Mohammed Al Zahrani' \\ Yousif Alalawi' \\ Umar Yagoub ${ }^{2}$ \\ Nooralsbah Saud' \\ Kashif Siddig' \\ 'Department of Surgery, King Salman \\ Armed Forces Hospital, Northwestern \\ Region, Tabuk 7I4II, Saudi Arabia; \\ ${ }^{2}$ Research Unit, Department of Academic \\ Affairs, King Salman Armed Forces \\ Hospital, Northwestern Region, Tabuk \\ 7|4II, Saudi Arabia
}

Background: Assessment of quality of life can significantly impact the diagnosis and treatment course of breast cancer, resulting in a better prognosis among patients. However, very limited data are available regarding quality of life among breast cancer patients in Saudi Arabia.

Objective: To determine the quality of life of women with breast cancer referred to the Surgery Department of King Salman Armed Forces Hospital for treatment and follow-up.

Materials and methods: This cross-sectional study used a questionnaire to assess the quality of life of 96 adult Saudi female patients diagnosed with breast cancer from January 2016 to September 2017.

Results: One-third of the surveyed patients (31.3\%) were $>48$ years of age, and $29.2 \%$ were in the 18 - to 27 -year age group. Regarding marital status, $35.4 \%$ of the women were married and $8.3 \%$ were single. The highest score was observed for the physical well-being subscale (7.65 \pm 071$)$, followed by the spiritual well-being subscale $(7.19 \pm 0.66)$, psychological wellbeing scale $(7.09 \pm 0.30)$ and social concerns subscale (7.02 \pm 0.41$)$. Age, marital status and cancer stage differed remarkably $(P=0.00)$ for the physical well-being subscale scores. Meanwhile, employed women differed significantly $(P=0.01)$ in terms of psychological well-being compared to those who were not employed. The social well-being subscale score of single and married women was significantly higher than that of widowed and divorced women. Women who underwent radiation and immunotherapy had significantly higher scores for the spiritual well-being subscale.

Conclusions: Scores were determined for the physical, spiritual, psychological and social well-being scales. Age, marital status and cancer stage significantly influenced the physical well-being scale; the occupation status of the patients significantly impacted the psychological well-being scale. Social well-being can be predicted by marital status, and chemotherapy and radiation significantly impacted the spiritual well-being scale.

Keywords: cross-sectional study, QOL instrument, independent $t$-test, ANOVA analysis, test-retest, immunotherapy

\section{Introduction}

In 2010, breast cancer was ranked 9th as the most common cause of mortality among females in Saudi Arabia. ${ }^{1,2}$ According to Saudi National Cancer registry statistics, the rate of newly diagnosed breast cancer increased from $19.1 \%$ (1996 report) to $25.8 \%$ (2012) of patients. ${ }^{3}$ The incidence of breast cancer cases is expected to increase in the Kingdom of Saudi Arabia in the coming few years because of aging and population growth. ${ }^{4}$

\section{Zahrani}

Department of Surgery, King Salman

Armed Forces Hospital, Northwestern

Region, P.O. Box 100, Tabuk 7I4II, Saudi Arabia

Tel +9 66I 4441088 Ext. (858I8)

Email mohammedumar200I@yaoo.com 
Diagnosis and treatment of breast cancer may result in physical and emotional distress due to fear of death, treatment side effects and feelings of social devaluation. ${ }^{5}$ Patients undergoing breast cancer treatment may suffer functional inability, altered self-image, loss of breast sensitivity, anxiety, depression and other emotional and psychological alterations. ${ }^{6}$

Breast cancer patients undergo many treatments, such as surgery, chemotherapy, radiotherapy and hormonal therapy. Some patients undergo a combination of treatments depending on the cancer type, stage, and size, as well as their demographics and clinical history. ${ }^{7}$

An increase in the survival rate of patients with breast cancer has been observed, which has diverted the attention of clinicians to assessing the impact of various treatments on the health-related quality of life (QOL) of patients. ${ }^{8}$ Studies have reported wide and frequent use of QOL assessments among cancer patients. According to the findings of a systematic review of QOL data, $30.1 \%$ of the medical and $63.2 \%$ of the non-biomedical interventions had an impact on QOL. ${ }^{9}$ QOL can help to alter treatment plans or it can be contingent on treatment plans for patients.

Few studies have been reported from Saudi Arabia regarding the QOL of breast cancer survivors. According to the results of a recent study, breast cancer survivors had low QOL. Patients' scores were averaged for the function scale, but patients scored higher on the emotional scale. ${ }^{10}$

QOL is a complex and a multidimensional measure that encompasses the diagnostic impact, the impact of disease treatment and its progression on daily routine activities and recovery of patients with breast cancer. Currently in oncology, QOL is considered to be an indicator for assessing the quality of care and its management. QOL subjectively assesses psychological, physical and social well-being and provides insight into daily living during the treatment of breast cancer. ${ }^{11,12}$

Limited information is available on the QOL of breast cancer patients in Saudi Arabia. Recently, QOL became the focus point for clinicians with regard to quality of diagnosis and survivorship of patients diagnosed with breast cancer. To date, no study has been published from the Northwestern region of Saudi Arabia addressing the QOL of breast cancer patients. Therefore, we designed this study to assess the quality of breast cancer patients in this region. This study aimed to determine the QOL of women with breast cancer who underwent treatment and follow-up at the Surgery Department of King Salam Armed Forces Hospital in the Northwestern Region in Tabuk, Saudi Arabia.

\section{Methods \\ Data collection}

This cross-sectional study was conducted at King Salman Armed Forces Hospital in the Northwestern Region in Tabuk, Saudi Arabia. Data collection was conducted through a structured questionnaire consisting of two portions. The first portion included demographic-, diseaseand treatment-related information, and the second portion consisted of a specific questionnaire regarding the QOL of breast cancer patients. A trained research assistant distributed the questionnaire among the patients.

\section{Sample size}

A total of 110 women were included in the study. Among these women, 4 were excluded as they did not fulfill the inclusion criteria. The final sample size was 96. The determination of the sample size is a crucial step in the design of a study.

\section{Sampling technique}

Sample selection was performed using a nonprobability purposive sampling technique. Patients were identified based on their medical files in the medical records department, and patients were included after fulfillment of the set inclusion criteria.

\section{Inclusion \& exclusion criteria}

Female patients diagnosed with breast cancer who were treated at the Oncology/Surgical Department of King Salam Armed Forces Hospital in Tabuk from January 2016 to September 2017 were included in the study. Only Saudi national females aged $>18$ years presenting with a first-time breast cancer diagnosis and receiving treatment were included in the study. Other nationalities were excluded to overcome bias regarding ethnicity. The exclusion criteria were patients aged $\leq 18$ years, prior history of breast cancer, non-Saudi females (to avoid bias), patients with disease recurrence, patients presenting with other malignancies or other comorbidities, patients in critical condition and patients with any mental or psychiatric ailments.

\section{QOL instrument}

Assessment of QOL was performed using the Quality of Life Instrument - Breast Cancer Patient (QOL-BC) instrument developed by Ferrel and Grant. ${ }^{13}$ This questionnaire consists of 46 questions arranged on an ordinal scale. The 
46 questions cover 4 domains of QOL (physical wellbeing, psychological well-being, social well-being and spiritual well-being), and each domain consists of a set of questions: physical well-being (8 items), psychological well-being (22 items), social well-being (9 items) and spiritual well-being ( 7 items). For each question, scoring was performed using a visual analog scale ranging from 0 to 10 , where 0 represents the best outcome and 10 represents the worst outcome. When encoding the response score, the scores were reversed for the following items: questions $1-7,9,10,17-29,31,33-39$ and 43. The subscale score was calculated by summing the scores of all of the questions to generate a mean score in that specific subscale/domain. This instrument was translated from English to Arabic by two bilingual language expert instructors in the academic affairs department. The translators were asked to perform a semantic translation, and the study instrument (questionnaire) was then checked for accuracy of translation

\section{Reliability and validity of the study instrument}

After development of the study questionnaire, the stability and reliability were assessed using a test-retest analysis by conducting data collection from 10 participants twice within a 2-week period and comparing the results. After reliability testing, face validity testing, which concerns the appearance of the questionnaire measurements, was performed.

\section{Pilot study}

A pilot study was conducted to examine the accuracy of the translated questionnaire and to identify certain deficiencies/mistakes in the study so that they could be corrected/improved before starting data collection from the target population.

\section{Statistical analysis}

Data entry and analysis were performed using SPSS version 23. Before analysis, data were cleaned and preprocessed, which involved checking their accuracy, treatment of missing values, and categorization and recoding of fields. Qualitative/categorical data (demographic characteristics) are presented as frequencies and percentages, and quantitative data (QOL subscale score) are presented as the mean $\pm \mathrm{SD}$. The mean score for each subscale of the QOL instrument (physical, psychological, social and spiritual subscale) was compared across sociodemographic and clinical characteristics of the patients by analysis of variance (ANOVA) and an independent sample $t$-test. $P$ values $\leq 0.05$ were considered significant.

\section{Ethical approval}

This study was conducted in accordance with the Declaration of Helsinki. Ethical approval of the study was obtained from the Ethical Review Committee of the King Salman Armed Forces Hospital. After obtaining written informed consent from the patients/attendants, the research assistant briefly explained the purpose of the study and provided assurance regarding maintaining the privacy, confidentiality and security of the data.

\section{Results}

\section{Demographic characteristics of patients}

In this study, $31.3 \%$ of the patients were $>48$ years old and $29.2 \%$ were $18-27$ years old. Regarding marital status, $35.4 \%$ of the women were married and $8.3 \%$ were single. Among these women, $42.7 \%$ had a secondary school education and $4.2 \%$ had no schooling. Of the total study participants, only $25 \%$ of the women were employed. Only $17.7 \%$ of the study participants had income levels $<5,000$ SR. (Table 1)

\section{Clinical and treatment-related characteristics of patients}

Cancer staging of patients showed that $40.6 \%$ of patients had stage II and $59.5 \%$ of the patients had stage III/IV cancer. Metastasis was reported by $12.5 \%$ of the patients. Regarding treatment, 71 (74\%) patients underwent surgery, $42(43.8 \%)$ patients were receiving chemotherapy, $46(47.9 \%)$ patients were receiving radiation therapy and $57(59.4 \%)$ patients were receiving immunotherapy. (Table 1)

\section{QOL item scores}

The highest score in the physical well-being subscale was observed for sleep changes (7.85 \pm 1.68$)$, followed by weight gain (7.74 \pm 1.68$)$, fatigue (7.71 \pm 1.62$)$ and appetite changes (7.68 \pm 1.72$)$. The highest score in the psychological wellbeing subscale was observed for control of current situation in life (8.57 \pm 1.11$)$, followed by fear of a second cancer ( 8.54 $\pm 1.15)$, fear of metastasis $(8.53 \pm 1.12)$ and fear of recurrence

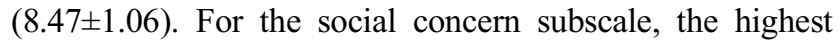
score was observed for home activities $(7.46 \pm 1.88)$, followed 
Table I Sociodemographic characteristics of the study participants $(n=96)$

\begin{tabular}{|c|c|c|c|}
\hline \multicolumn{2}{|c|}{ Characteristic } & \multirow{2}{*}{$\begin{array}{l}\text { Number } \\
28\end{array}$} & \multirow{2}{*}{$\begin{array}{l}\text { Percentage } \\
29.2\end{array}$} \\
\hline Age (years) & $18-27$ & & \\
\hline & $28-37$ & 22 & 22.9 \\
\hline & $38-47$ & 16 & 16.7 \\
\hline & $>48$ & 30 & 31.3 \\
\hline & Total & 96 & 100 \\
\hline \multirow[t]{5}{*}{ Marital status } & Single & 8 & 8.3 \\
\hline & Married & 34 & 35.4 \\
\hline & Divorced & 23 & 24.0 \\
\hline & Widowed & 31 & 32.3 \\
\hline & Total & 96 & 100 \\
\hline \multirow[t]{6}{*}{ Education level } & No schooling & 4 & 4.2 \\
\hline & Primary school & 26 & 27.1 \\
\hline & Secondary school & 41 & 42.7 \\
\hline & Graduate level & 16 & 16.7 \\
\hline & Postgraduate level & 9 & 9.4 \\
\hline & Total & 96 & 100 \\
\hline \multirow[t]{3}{*}{ Occupation } & Employed & 24 & 25.0 \\
\hline & Not Employed & 72 & 75.0 \\
\hline & Total & 96 & 100 \\
\hline \multirow[t]{6}{*}{ Income (SAR) } & $<5000$ & 17 & 17.7 \\
\hline & $500 I-1000$ & 44 & 45.8 \\
\hline & $10001-15000$ & 23 & 24.0 \\
\hline & $|500|-20000$ & 7 & 7.3 \\
\hline & 20000 & 5 & 5.2 \\
\hline & Total & 96 & 100 \\
\hline \multirow[t]{3}{*}{ Cancer stage } & $\mathrm{I} / \mathrm{II}$ & 39 & 40.6 \\
\hline & III/IV & 57 & 59.4 \\
\hline & Total & 96 & 100 \\
\hline \multirow[t]{3}{*}{ Multiple tumors } & Yes & 19 & 19.8 \\
\hline & No & 77 & 80.2 \\
\hline & Total & 96 & 100 \\
\hline
\end{tabular}

(Continued)
Table I (Continued).

\begin{tabular}{|c|c|c|c|}
\hline \multicolumn{2}{|c|}{ Characteristic } & \multirow{2}{*}{$\frac{\text { Number }}{12}$} & \multirow{2}{*}{$\begin{array}{l}\text { Percentage } \\
12.5\end{array}$} \\
\hline Metastasis & Yes & & \\
\hline & No & 84 & 87.5 \\
\hline & Total & 96 & 100 \\
\hline \multirow[t]{3}{*}{ Cancer surgery } & Yes & 71 & 74.0 \\
\hline & No & 25 & 26.0 \\
\hline & Total & 96 & 100 \\
\hline \multirow[t]{3}{*}{ Chemotherapy } & Yes & 42 & 43.8 \\
\hline & No & 54 & 56.3 \\
\hline & Total & 96 & 100 \\
\hline \multirow[t]{3}{*}{ Radiation } & Yes & 46 & 47.9 \\
\hline & No & 50 & 52.1 \\
\hline & Total & 96 & 100 \\
\hline \multirow[t]{3}{*}{ Immunotherapy } & Yes & 57 & 59.4 \\
\hline & No & 39 & 40.6 \\
\hline & Total & 96 & 100 \\
\hline
\end{tabular}

by sexuality (7.31 \pm 1.86$)$, employment $(7.18 \pm 2.02)$ and feeling of isolation (7.18 \pm 1.76$)$. In the spiritual well-being subscale, the highest score was observed for hopefulness (7.50 \pm 1.49 ), followed by positive changes $(7.29 \pm 1.85)$ and changes in spiritual life (7.22 \pm 1.68$)$. (Table 2)

\section{QOL subscale scores}

Table 2 shows the QOL subscale scores of breast cancer patients. The physical well-being subscale (7.65 \pm 071$)$ exhibited the highest score, followed by the spiritual well-being subscale (7.19 \pm 0.66$)$, psychological wellbeing subscale $(7.09 \pm 0.30)$ and social concerns subscale (7.02 \pm 0.41$)$ (Table 2).

\section{QOL subscale domain scores in relation}

\section{to demographic and clinical}

\section{characteristics of the patients}

Age (patients $>48$ had the highest scores, and patients in the younger age group had the lowest scores), marital status (widow and divorced women had higher scores) and cancer stage (patients with stage I/II cancer had higher 
Table 2 QOL-BC (Items by subscale) - N=96

\begin{tabular}{|c|c|c|c|c|c|}
\hline \multicolumn{4}{|c|}{ Characteristic } & \multirow[t]{2}{*}{ Mean } & \multirow[t]{2}{*}{ SD } \\
\hline \multicolumn{2}{|c|}{ Physical well-being } & Mean & SD & & \\
\hline I & Fatigue & 7.71 & 1.62 & \multirow[t]{8}{*}{7.65} & \multirow[t]{8}{*}{0.71} \\
\hline 2 & Appetite changes & 7.68 & 1.72 & & \\
\hline 3 & Aches or pain & 7.65 & 1.65 & & \\
\hline 4 & Sleep changes & 7.85 & 1.68 & & \\
\hline 5 & Weight gain & 7.74 & 1.68 & & \\
\hline 6 & Vaginal dryness/menopausal symptoms & 7.56 & 1.72 & & \\
\hline 7 & Menstrual changes or fertility & 7.38 & 1.74 & & \\
\hline 8 & Overall physical health & 7.57 & 1.75 & & \\
\hline \multicolumn{2}{|c|}{ Psychological well-being } & Mean & SD & & \\
\hline 9 & Coping with disease & 6.45 & 2.24 & \multirow[t]{22}{*}{7.09} & \multirow[t]{22}{*}{0.30} \\
\hline 10 & Coping with treatment & 7.52 & 1.65 & & \\
\hline II & QOL & 7.91 & 1.54 & & \\
\hline 12 & Happiness & 6.72 & 2.15 & & \\
\hline 13 & Control & 8.57 & 1.11 & & \\
\hline 14 & Satisfaction & 6.38 & 2.20 & & \\
\hline 15 & Concentration/memory & 6.36 & 1.05 & & \\
\hline 16 & Usefulness & 7.18 & 1.41 & & \\
\hline 17 & Appearance & 6.65 & 1.13 & & \\
\hline 18 & Self-concept & 6.61 & 1.10 & & \\
\hline 19 & Initial diagnosis distress & 6.54 & 1.11 & & \\
\hline 20 & Chemotherapy distress & 6.37 & 2.09 & & \\
\hline 21 & Radiation distress & 6.59 & 1.01 & & \\
\hline 22 & Surgery distress & 6.65 & 1.02 & & \\
\hline 23 & Treatment completion distress & 6.38 & 1.14 & & \\
\hline 24 & Anxiety & 6.14 & 1.03 & & \\
\hline 25 & Depression & 6.50 & 1.04 & & \\
\hline 26 & Fear of future diagnostic tests & 6.39 & 1.07 & & \\
\hline 27 & Fear of a second cancer & 8.54 & 1.15 & & \\
\hline 28 & Fear of recurrence & 8.47 & 1.06 & & \\
\hline 29 & Fear of metastasis & 8.53 & 1.12 & & \\
\hline 30 & Normal life & 8.54 & 1.16 & & \\
\hline \multicolumn{2}{|c|}{ Social well-being } & Mean & SD & & \\
\hline
\end{tabular}


Table 2 (Continued).

\begin{tabular}{|c|c|c|c|c|c|}
\hline \multicolumn{4}{|c|}{ Characteristic } & Mean & SD \\
\hline 31 & Family distress & 6.88 & 1.84 & \multirow[t]{9}{*}{7.02} & \multirow[t]{9}{*}{0.41} \\
\hline 32 & Support/Others & 6.93 & 1.73 & & \\
\hline 33 & Personal relationships & 6.95 & 1.93 & & \\
\hline 34 & Sexuality & 7.31 & 1.86 & & \\
\hline 35 & Employment & 7.18 & 2.02 & & \\
\hline 36 & Home activities & 7.46 & 1.88 & & \\
\hline 37 & Feeling isolated & 7.18 & 1.76 & & \\
\hline 38 & Concern for daughter/close female relatives & 7.09 & 1.64 & & \\
\hline 39 & Financial burden & 7.12 & 1.63 & & \\
\hline \multicolumn{2}{|c|}{ Spiritual well-being } & Mean & SD & \multirow[t]{8}{*}{7.19} & \multirow[t]{8}{*}{0.66} \\
\hline 40 & Religious activities & 6.80 & 1.85 & & \\
\hline 41 & Spiritual activities & 7.08 & 1.72 & & \\
\hline 42 & Spiritual life changed & 7.22 & 1.68 & & \\
\hline 43 & Uncertainty & 7.14 & 1.74 & & \\
\hline 44 & Positive changes & 7.29 & 1.85 & & \\
\hline 45 & Life purpose/Mission & 7.29 & 1.71 & & \\
\hline 46 & Hopefulness & 7.50 & 1.49 & & \\
\hline
\end{tabular}

scores) were associated with significant differences in the physical well-being subscale score. Women who were employed had significantly higher psychological wellbeing scores than women who were not employed. Single and married women had significantly higher social well-being subscale scores than widowed and divorced women. Women who underwent radiation and immune therapy had significantly higher scores for the spiritual well-being subscale. (Table 3)

\section{Discussion}

This study aimed to assess the QOL of Saudi women with breast cancer receiving treatment in the Surgery Department of King Salman Armed Forces Hospital of the Northwestern Region of Tabuk, Saudi Arabia. The QOL of these women was compared according to their sociodemographic and clinical characteristics to determine the impact of these factors on their daily lives. Currently, assessment of QOL is an essential component of clinical cancer research and trails; nevertheless, limited information is available regarding the QOL
Saudi breast cancer patients. The results of this study showed that the mean score for physical well-being $(7.65 \pm 0.71)$ was highest among the women, followed by spiritual well-being (7.19 \pm 0.66$)$, psychological well-being (7.09 \pm 0.30$)$ and social well-being $(7.02 \pm 0.41)$.

In this study, the mean score of the physical well-being scale showed significant differences with respect to age and marital status of women. Elderly patients and patients who were divorced and widowed reported higher scores, indicating poorer physical function.

This finding is supported by the results of Anwar E Ahmed's study, which reported poorer function in elderly patients. ${ }^{7}$ The study also reported that patients with higher education levels had good physical function. Contrary to this finding, in this study, women with higher education levels had poor physical well-being scores compared to women with less education. Studies have shown a negative age effect and a positive effect of education on QOL. ${ }^{4,7}$ Previous studies have reported that patients with multiple tumors and metastasis tend to have poor QOL. ${ }^{7,14,15}$ The 


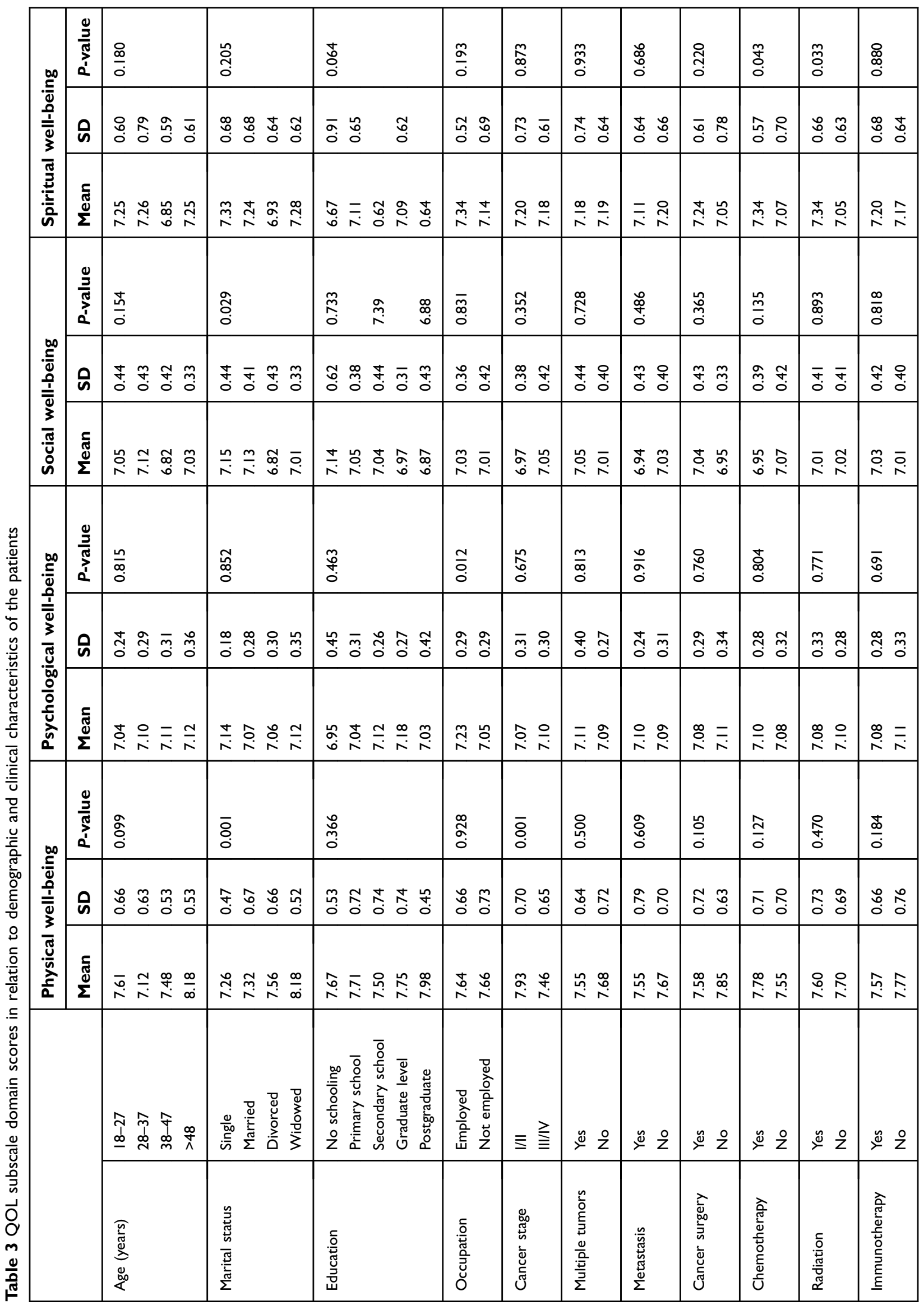


same trend regarding multiple tumors and metastatic disease was observed in this study. These patients had high scores on the physical, psychological, social and spiritual well-being scales, indicating difficulty and poor QOL. In this study, of the items on the physical well-being scale, vaginal dryness/menopausal symptoms and menstrual changes or fertility showed the lowest scores. In Islamic countries, women are hesitant to discuss such issues with health care providers unless the treating physician is female.

In this study, the psychological scores showed the difficulty that patients had regarding insight into their disease. Life-threatening diseases such as cancer can easily provoke distress, fear, anxiety and depression. According to the results of a previous study from the Kingdom of Saudi Arabia, psychological distress (anxiety and somatization) is increased in breast cancer patients. ${ }^{16}$ Other studies have reported similar findings regarding psychological distress among breast cancer patients. ${ }^{17,18}$ Miri Cohen reported that $28 \%$ of the variance in psychological distress was explained by an interaction between group perceived support and group body image. ${ }^{16}$ Another study reported that psychological distress explains $63 \%$ of variance in the QOL of breast cancer patients. ${ }^{19}$ In this study, psychological well-being scores were significantly higher in women who were employed than in unemployed women. Because an employed person needs frequent/long vacations from work for cancer treatment and diagnosis, they incur an additional financial burden, which ultimately triggers the fear of job loss.

For the social well-being subscale, the highest score was observed for home activities, followed by sexuality, concern/ fear regarding occurrence of breast cancer in a daughter/close female relative and financial burden. Previous studies have also reported such fear of breast cancer occurrence in close family members or among siblings. ${ }^{18,20}$ Household activities can be influenced based on cultural and social norms. In Islamic/traditional societies, it is the responsibility of the mother to perform all household activities. ${ }^{21}$ Miri Cohen reported that women with breast cancer reported a higher degree of sharing household tasks. ${ }^{16}$ Married and single women in this study showed significantly higher scores for the social well-being subscale. None of the other variables had a significant effect on the social well-being of breast cancer patients.

Patients in this study showed a high mean score for the spiritual well-being scale, indicating their positive approach and affiliation with spiritual and religious activity, as well as positive changes and hopefulness towards their health and complete recovery. As a Muslim, a relationship with God and other religious activities provokes a sense of comfort and ease among patients with a more positive attitude toward their disease. Studies have recognized religiosity/spirituality as a predictor of health-related QOL in cancer survivors, and some studies have reported a positive relationship between religiosity/spirituality and QOL. ${ }^{22,23}$ Studies have shown that religiosity/spirituality affects the QOL in a positive way by helping the patients to cope with pain, symptoms and other life-threating aspects of cancer. $^{24}$ Kimberly A. Wildes reported a positive correlation between religiosity/spirituality and social and functional well-being. ${ }^{22}$

Taking into account the above discussion, our findings cannot be directly compared to those of other studies for reasons such as cultural differences and the instrument used to assess the QOL of patients. However, the important aspects that can influence the QOL of breast cancer patients can be utilized by health care providers for effective prediction and proper management of breast cancer patients in this region.

\section{Study limitations, significance and future work}

This study had several limitations, such as recall bias associated with self-reported questionnaires, as some patients may not remember the answers to some questions. This bias was minimized by ensuring proper definition of the research question and improving the quality of the questionnaire. Selection bias was also overcome using appropriate sampling methods. Another limitation was the inability to include some specific domains for breast cancer. The significance of this study is that it highlights the effect of the disease and associated factors on the QOL of breast cancer patients. The authors intend to conduct a similar study using a major QOL assessment tool for breast cancer such as the Functional Assessment of Cancer Therapy - Breast Cancer (FACT-B) or European Organisation for Research and Treatment of Cancer (EORTC) instrument in the near future.

\section{Conclusion}

QOL was assessed in patients diagnosed with breast cancer who were undergoing treatment and follow-up at King Salman Armed Forces Hospital in Tabuk city, in the northeast corner of Saudi Arabia. The study revealed increased scores for the physical, spiritual, psychological and social well-being subscales. Age, marital status and cancer stage 
had a remarkable influence on the physical well-being subscale, whereas work status significantly influenced the psychological well-being subscale. In contrast, certain demographic characteristics of the patients, namely, marital status, chemotherapy and radiation, could act as predictive indicators of the social well-being (ie, marital status) and spiritual well-being (ie, chemotherapy and radiation) subscales. Assessment of such indicators can help clinicians and decision-makers to forecast future barriers and plan for proper interventions that can improve the QOL of patients with breast cancer.

\section{Acknowledgments}

The authors are very grateful for the generous support provided by the Research Department, Academic Affairs and Hospital Administration of King Salman Armed Forces Hospital, Northwestern Region, Tabuk, Saudi Arabia. The authors appreciate the unreserved efforts made by Mr. Marwan Manajreh during the data collection and entry process. The authors would also like to thank Ms. Sunu Krishan for her administrative and secretarial support during the study.

\section{Disclosure}

The authors declare that they have no conflicts of interest in this work.

\section{References}

1. Mokdad AH, Jaber S, Aziz MI, et al. The state of health in the Arab world, 1990-2010: an analysis of the burden of diseases, injuries, and risk factors. Lancet. 2014;383(9914):309-320. doi:10.1016/S01406736(13)62189-3

2. Lozano R, Naghavi M, Foreman K, et al. Global and regional mortality from 235 causes of death for 20 age groups in 1990 and 2010: a systematic analysis for the Global burden of disease study 2010 Lancet. 2012;380(9859):2095-2128. doi:10.1016/S0140-6736(12) 61728-0

3. Mokrini F, Waeyenberge L, Viaene N, Moens, M. First Report of the cereal cyst nematode Heterodera Iatipons on wheat in Morocco. Plant Disease. 2012:96(5):774.

4. Ibrahim EM, Zeeneldin AA, Sadiq BB, Ezzat AA. The present and the future of breast cancer burden in the Kingdom of Saudi Arabia. Med Oncol. 2008;25(4):387-393. doi:10.1007/s12032-008-9051-5

5. Lara LA, de Andrade JM, Consolo FD, Romao AP. Women's poorer satisfaction with their sex lives following gynecologic cancer treatment. Clin J Oncol Nurs. 2012;16(3):273-277. doi:10.1188/12. CJON.273-277

6. Paterson CL, Lengacher CA, Donovan KA, Kip KE, Tofthagen CS. Body image in younger breast cancer survivors: a systematic review. Cancer Nurs. 2016;39(1):0000000000000251.
7. Ahmed AE, Alharbi AG, Alsadhan MA, et al. The predictors of poor quality of life in a sample of Saudi women with breast cancer. Breast Cancer. 2017;9:51.

8. Zaid LZA, Nuzhat A, Rafiqe M. Factors affecting survival of women with breast cancer in King Fahad Medical City, Saudi Arabia. Int $J$ Community Med Publ Health. 2017;4(4):910-915. doi:10.18203/ 2394-6040.ijcmph20171306

9. Lemieux J, Goodwin PJ, Bordeleau LJ, Lauzier S, Théberge V. Quality-of-life measurement in randomized clinical trials in breast cancer: an updated systematic review (2001-2009). J Natl Cancer Inst. 2011;103(3):178-231. doi:10.1093/jnci/djq508

10. Almutairi K, Mansour E, Vinluan J. A cross-sectional assessment of quality of life of breast cancer patients in Saudi Arabia. Public Health. 2016;136:117-125. doi:10.1016/j.puhe.2016.03.008

11. Ferrell BR, Grant M, Funk B, Otis-Green S, Garcia N. Quality of life in breast cancer: part I physical and social well-being. Cancer Nurs. 1997;20(6):398-408.

12. Ferrell BR, Grant M, Funk B, Otis-Green S, Garcia N. Quality of life in breast cancer: part II psychological and spiritual well-being. Cancer Nurs. 1998;21(1):1-9.

13. Ferrell BR, Grant MM, Funk BM, Otis-Green SA, Garcia NJ. Quality of life in breast cancer survivors: implications for developing support services. Oncol Nurs Forum. 1998;25:887-895.

14. Wyatt G, Sikorskii A, Tamkus D, You M. Quality of life among advanced breast cancer patients with and without distant metastasis. Eur J Cancer Care (Engl). 2013;22(2):272-280. doi:10.1111/ ecc. 12028

15. Tang Z, Wang J, Zhang H, et al. Associations between diabetes and quality of life among breast cancer survivors. PLoS One. 2016;11(6): e0157791. doi:10.1371/journal.pone.0157791

16. Cohen M, Mabjish AA, Zidan J. Comparison of Arab breast cancer survivors and healthy controls for spousal relationship, body image, and emotional distress. Qual Life Res. 2011;20(2):191-198. doi:10.1007/s11136-010-9747-9

17. Abu-Helalah M, Al-Hanaqta $M$, Alshraideh $\mathrm{H}$, Abdulbaqi N, Hijazeen J. Quality of life and psychological well-being of breast cancer survivors in Jordan. Asian Pac J Cancer Prev. 2014;15 (14):5927-5936.

18. Rahou BH, El Rhazi K, Ouasmani F, et al. Quality of life in Arab women with breast cancer: a review of the literature. Health Qual Life Outcomes. 2016;14(1):64. doi:10.1186/s12955-016-0426-6

19. Ursaru M, Crumpei I, Crumpei G. Quality of life and religious coping in women with breast cancer. Procedia-Social Behav Sci. 2014;114:322-326. doi:10.1016/j.sbspro.2013.12.705

20. Costa-Requena G, Rodríguez A, Fernández-Ortega P. Longitudinal assessment of distress and quality of life in the early stages of breast cancer treatment. Scand J Caring Sci. 2013;27(1):77-83. doi:10.1111/j.1471-6712.2012.01003.x

21. Greenstein TN. Husbands' participation in domestic labor: interactive effects of wives' and husbands' gender ideologies. J Marriage Fam. 1996;585-595. doi:10.2307/353719

22. Wildes KA, Miller AR, de Majors SSM, Ramirez AG. The religiosity/spirituality of latina breast cancer survivors and influence on health-related quality of life. Psycho-Oncology. 2009;18(8):831840. doi:10.1002/pon. 1475

23. Hill PC, Pargament KI. Advances in the conceptualization and measurement of religion and spirituality. Implications for physical and mental health research. Am Psychol. 2003;58(1):64-74.

24. Brady MJ, Peterman AH, Fitchett G, Mo M, Cella D. A case for including spirituality in quality of life measurement in oncology. Psychooncology. 1999;8(5):417-428. 


\section{Publish your work in this journal}

Breast Cancer - Targets and Therapy is an international, peer-reviewed open access journal focusing on breast cancer research, identification of therapeutic targets and the optimal use of preventative and integrated treatment interventions to achieve improved outcomes, enhanced survival and quality of life for the cancer patient.
The manuscript management system is completely online and includes a very quick and fair peer-review system, which is all easy to use. Visit http://www.dovepress.com/testimonials.php to read real quotes from published authors.

Submit your manuscript here: https://www.dovepress.com/breast-cancer-targets-and-therapy-journal 